\title{
Association of apolipoprotein E genotypes, blood pressure, blood lipids and ECG abnormalities in a general population aged 85+
}

\author{
Sari Rastas*1, Kimmo Mattila², Auli Verkkoniemi ${ }^{3}$, Leena Niinistö ${ }^{4}$, \\ Kati Juva ${ }^{5}$, Raimo Sulkava ${ }^{6}$ and Esko Länsimies ${ }^{7}$
}

\begin{abstract}
Address: ${ }^{1}$ Department of Neuroscience and Neurology, University of Kuopio, Kuopio, Finland, ${ }^{2}$ Division of Infectious Diseases, Department of Medicine, Helsinki University Central Hospital, Helsinki, Finland, ${ }^{3}$ Department of Clinical Neurosciences, Helsinki University Central Hospital, Helsinki, Finland, ${ }^{4}$ Katriina Community Hospital, Vantaa, Finland, ${ }^{5}$ Department of Psychiatry, Helsinki University Central Hospital, Helsinki, Finland, ${ }^{6}$ Department of Public Health and General Practice, University of Kuopio, Kuopio, Finland and ${ }^{7}$ Department of clinical Physiology and Nuclear Medicine, University and University Hospital, Kuopio, Finland

Email: Sari Rastas* - Sari.Rastas@kolumbus.fi; Kimmo Mattila - Kimmo.Mattila@hus.fi; Auli Verkkoniemi - auli@doctor.com; Leena Niinistö - Leena.Niinisto@vantaa.fi; Kati Juva - katijuva@katto.kaapeli.fi; Raimo Sulkava - Raimo.Sulkava@uku.fi; Esko Länsimies - Esko.Lansimies@kuh.fi

* Corresponding author
\end{abstract}

Published: 29 March 2004

BMC Geriatrics 2004, 4:I
Received: 17 September 2003

Accepted: 29 March 2004

This article is available from: http://www.biomedcentral.com/I47I-23/8/4/I

(c) 2004 Rastas et al; licensee BioMed Central Ltd. This is an Open Access article: verbatim copying and redistribution of this article are permitted in all media for any purpose, provided this notice is preserved along with the article's original URL.

\begin{abstract}
Background: Several studies have linked apolipoprotein E (ApoE) $\varepsilon 4$ allele with elevated cholesterol and blood pressure levels. Data on the association of APOE genotypes with blood pressure, lipids, atrial fibrillation and ECG abnormalities in individuals aged 85 years and over is sparse.
\end{abstract}

Methods: This cross sectional study consisted of all residents of the city of Vantaa $(\mathrm{N}=60 \mathrm{I})$ aged 85 years or over of whom 505 participated in the study. Blood pressure was measured by using mercury sphygmomanometer. I2-Lead ECG, short ambulatory ECG, or both were taken from all study subjects to diagnose atrial fibrillation (AF). Ambulatory ECG was carried out home or in the institute. APOE genotyping was performed using a combination of the polymerase chain reaction (PCR) and solid-phase minisequencing technique. Statistical analysis was made by using KruskallWallis-test (continuous data) and $\chi^{2}$-test (rates and proportions).

Results: In these very elderly individuals, APOE 4 allele was significantly associated with elevated cholesterol and low-density lipoprotein (LDL) levels. Blood pressure or cardiac arrhythmias did not differ between APOE genotypes.

Conclusions: These observations suggest that the important role of APOE genotype still influences cardiovascular risk profile even among the very elderly people.

\section{Background}

Apolipoprotein E (ApoE) has an important role in the regulation of plasma cholesterol concentration. It also mediates the receptor uptake of triglyceride rich lipoproteins and may participate in reverse cholesterol transport $[1,2]$. ApoE is polymorphic and exists in three protein isoforms designated E2, E3, and E4, [1,2] encoded by three alleles $\varepsilon 2, \varepsilon 3$ and $\varepsilon 4$ [3]. Genotypes $\varepsilon 4 / \varepsilon 4$ and $\varepsilon 4 / \varepsilon 3$ are associated with a high cholesterol concentration $[4,5]$. Thus ApoE polymorphism may influence the risk of atherosclerosis [4]. An association between the APOE $\varepsilon 4$ and $\varepsilon 2$ alleles with high blood pressure, and especially, with high 
systolic blood pressure has been observed [6,7]. However, lack of association with high blood pressure has also been reported [8-10].

\section{Methods}

The Vantaa $85+$ Study is a longitudinal population based study examining all residents of Vantaa, a city in Southern Finland, aged 85 years or over $(N=601)$ on April the first 1991. All persons whether living home or in institutions was asked to participate in the study. Altogether 553 $(92 \%)$ consented in the study, 36 persons had died, 11 persons refused to participated and one could not be reached. Of these 553 clinically examined subjects, APOE genotyping was available from $531(88.4 \%)$ subjects blood pressure measurement from $521(86.7 \%)$ and both from 505 (84.0\%). The Ethics Committee of the Helsinki University Central Hospital approved the study. An informed consent was obtained from all participants or from a close relative if a participant was demented.

A physician performed structured interviews including a history of cardiovascular symptoms and treatment. The data was also collected from a computerised primary health care record database. Physical examination of the subjects included cardiac auscultation and measurement of blood pressure and pulse rate. Blood pressure (systolic Korotkoff phase I and diastolic phase V) was measured with a calibrated mercury sphygmomanometer with the cuff on the right arm, the subject sitting after having rested for five minutes. The blood pressure of bedridden patients was measured in a recumbent position.

The analysis of ECG recordings included evaluation of arrhythmias and conduction abnormalities. Evaluation of the signs of coronary heart disease (CHD) was not performed. ECG recordings were performed with two methods. An ambulatory ECG monitoring technique with three exploring electrodes corresponding to leads V1 and V5 was used in 301 subjects and it was carried out at home or in the institute. The recording period ranged from 30 minutes to two hours with an average monitoring time of one hour. All the recordings were further analysed by the Reynolds TR1-Holter analysing equipment. Accuracy of reading was evaluated by analysing 10 registrations twice, there were no differences between these two analyses. Routine twelve lead resting ECGs were available from 204 subjects. One specialist performed all analyses.

Total serum cholesterol, high density lipoproteins (HDL), low density lipoproteins (LDL) and triglycerides were quantified by enzymatic techniques. APOE genotyping was performed using a combination of the polymerase chain reaction (PCR) and solid-phase minisequencing technique [11].

Statistical analysis was made by using Kruskall-Wallis-test (continuous data) and $\chi^{2}$-test (rates and proportions), with 7 SPSS for Windows program. No adjustment for multiple comparisons was made.

\section{Results}

The mean age of the study population $(\mathrm{N}=505)$ was 88.3 years (range 85-104 years). 107 (21.2\%) were males and $398(78.8 \%)$ females. The distribution of APOE allele frequencies were $\varepsilon 415.3 \%, \varepsilon 376.9 \%$, and $\varepsilon 27,8 \%$. These frequencies follow Hardy-Weinberg equilibrium, and agree with the previously reported allele frequencies in the elderly Finnish population [12].

The mean systolic and diastolic blood pressures were 149 $\mathrm{mmHg}$ (range $90-230 \mathrm{mmHg}$ ) and $82 \mathrm{mmHg}$ (range 45$120 \mathrm{mmHg}$ ), respectively. There was no association between systolic or diastolic blood pressure level and APOE genotypes (Table 1). As previously shown [13] total serum cholesterol levels differed significantly between different APOE genotypes, with $\varepsilon 3 / \varepsilon 4$ and $\varepsilon 4 / \varepsilon 4$ being associated with the highest levels (Table 2, $\mathrm{P}=0.02$ ). Also high LDL cholesterol level associated with $\varepsilon 3 / \varepsilon 4$ and $\varepsilon 4 / \varepsilon 4(\mathrm{P}=$ 0.001). The levels of triglycerides, or HDL cholesterol showed no association with APOE genotypes.

Table I: Systolic and diastolic blood pressures, and APOE genotypes in the study population ( $\mathbf{N}=505) . \mathrm{MmHg} \pm \mathrm{SD}$.

\begin{tabular}{cccc}
\hline APOE genotype & $\mathbf{N}(\%)$ in study population & Mean systolic BP & Mean diastolic BP \\
$\varepsilon \mathbf{2} / \varepsilon \mathbf{2}$ & $2(0.4)$ & $150 \pm 14.1$ & $85 \pm 7.1$ \\
$\varepsilon \mathbf{2} / \varepsilon \mathbf{3}$ & $62(12.3)$ & $149 \pm 25.5$ & $81 \pm 12.0$ \\
$\varepsilon \mathbf{2} / \varepsilon \mathbf{4}$ & $14(2.8)$ & $141 \pm 32.1$ & $76 \pm 13.4$ \\
$\varepsilon \mathbf{3} / \varepsilon \mathbf{3}$ & $294(58.2)$ & $150 \pm 28.1$ & $81 \pm 13.2$ \\
$\varepsilon \mathbf{3} / \varepsilon \mathbf{4}$ & $126(24.9)$ & $147 \pm 27.3$ & $82 \pm 12.3$ \\
$\varepsilon \mathbf{4} / \varepsilon \mathbf{4}$ & $7(1.4)$ & $132 \pm 27.3$ & $82 \pm 8.1$ \\
$\mathbf{P}$ & $505(100)$ & & 0.5 \\
Total & & & 0.7
\end{tabular}


Table 2: Blood lipids and APOE genotypes in the study population $(\mathbf{N}=505)$. Mmol \pm SD.

\begin{tabular}{ccccc}
\hline APOE Genotype & $\begin{array}{c}\text { Mean serum } \\
\text { cholesterol }\end{array}$ & $\begin{array}{c}\text { Mean serum } \\
\text { triglycerides }\end{array}$ & Mean serum HDL & Mean serum LDL \\
$\varepsilon \mathbf{2} / \varepsilon \mathbf{2}$ & $4.1 \pm 1.2$ & $1.7 \pm 0.5$ & $1.1 \pm 0.4$ & $2.2 \pm 0.9$ \\
$\varepsilon \mathbf{2} / \varepsilon \mathbf{3}$ & $5.1 \pm 1.2$ & $1.9 \pm 0.8$ & $1.0 \pm 0.3$ & $3.2 \pm 1.1$ \\
$\varepsilon \mathbf{2} / \varepsilon \mathbf{4}$ & $4.9 \pm 0.9$ & $1.4 \pm 0.5$ & $1.2 \pm 0.3$ & $3.1 \pm 0.9$ \\
$\varepsilon \mathbf{3} / \varepsilon \mathbf{3}$ & $5.4 \pm 1.3$ & $2.0 \pm 1.2$ & $1.0 \pm 0.3$ & $3.6 \pm 1.1$ \\
$\varepsilon \mathbf{3} / \varepsilon \mathbf{4}$ & $5.6 \pm 1.2$ & $2.0 \pm 1.2$ & $1.0 \pm 0.3$ & $3.8 \pm 1.1$ \\
$\varepsilon \mathbf{4} / \varepsilon \mathbf{4}$ & $6.0 \pm 2.1$ & $1.4 \pm 0.8$ & $1.0 \pm 0.2$ & 0.1 \\
$\mathbf{P}$ & 0.02 & 0.5 & 0.1 & 0.001 \\
\hline
\end{tabular}

APOE genotypes and ECG abnormalities are shown in table 3 . The genotype $\varepsilon 3 / \varepsilon 3$ seemed to be associated with the highest frequencies of chronic atrial fibrillation (AF) but the difference was of borderline statistical significance only. Extrasystolias or conduction disturbances were not associated with the APOE genotypes. There were also no differences between males and females regarding APOE and $\mathrm{AF}$, blood pressure or lipids.

\section{Discussion}

The association of various APOE genotypes with some prevalent diseases such as atherosclerosis and Alzheimer's disease has drawn a lot of attention during the last decade. Previous studies have consistently shown that APOE genotype contributes to cholesterol levels $[3,5]$. The present study shows that APOE genotype affects serum cholesterol and LDL-levels in the very elderly. However, there was no association between APOE genotype and some other cardiovascular risk factors such as systolic or diastolic blood pressure, and serum triglycerides. Although the occurrence of $A F$ was higher in individuals with allele $\varepsilon 3$, there were no statistically significant relationships between
APOE genotype and the presence of arrhythmias or conduction abnormalities.

It is well known that the $\varepsilon 4$ allele of APOE is associated with the increased prevalence of atherosclerosis and CHD $[4,13,14]$. However, there are controversial results concerning the association between apoE genotype and some cardiovascular risk factors. Previous studies have suggested that high blood pressure may be associated with the presence of the $\varepsilon 4$ allele $[6,15,16]$, others have found an association with $\varepsilon 2$ allele and hypertension [7], and no association were found in some studies [8-10]. ApoE may interfere with smooth muscle cell proliferation [17] and thus participate in smooth muscle cell hypertrophy in the arterial wall. These mechanisms may explain the association in young or middle-aged populations that were mainly included in the previous studies. However, other mechanisms such as increased rigidity and decreased elasticity of the aorta and other large vessels [18] may contribute to the development of high blood pressure, and thus explain the lack of association in the very elderly.

Table 3: APOE genotypes, atrial fibrillation and ECG abnormalities in the study population. Total number and percentages of total (N = 505).

\begin{tabular}{ccccccc}
\hline $\begin{array}{l}\text { APOE } \\
\text { Genotype }\end{array}$ & $\begin{array}{l}\text { Atrial } \\
\text { fibrillation }\end{array}$ & $\begin{array}{l}\text { No atrial } \\
\text { fibrillation }\end{array}$ & VPB*or SVPB & $\begin{array}{l}\text { No VPB or } \\
\text { SVPB }\end{array}$ & $\begin{array}{l}\text { Conduction } \\
\text { disturbances }\end{array}$ & $\begin{array}{l}\text { No conduction } \\
\text { disturbances }\end{array}$ \\
\hline$\varepsilon 2 / \varepsilon 2$ & $I(0.2)$ & $I(0.2)$ & $0(0)$ & $2(0.4)$ & $0(0)$ & $2(0.4)$ \\
$\varepsilon 2 / \varepsilon 3$ & $7(1.4)$ & $53(10.5)$ & $35(6.9)$ & $26(5.1)$ & $9(1.8)$ & $52(10.3)$ \\
$\varepsilon 2 / \varepsilon 4$ & $1(0.2)$ & $13(2.6)$ & $8(1.6)$ & $6(1.2)$ & $4(0.8)$ & $10(2.0)$ \\
$\varepsilon 3 / \varepsilon 3$ & $54(10.7)$ & $240(47.5)$ & $122(24.2)$ & $173(34.3)$ & $25(4.9)$ & $269(53.3)$ \\
$\varepsilon 3 / \varepsilon 4$ & $20(4.0)$ & $107(21.2)$ & $55(10.9)$ & $70(13.9)$ & $10(1.9)$ & $116(23.0)$ \\
$\varepsilon 4 / \varepsilon 4$ & $3(0.6)$ & $5(0.9)$ & $2(0.4)$ & $6(1.1)$ & $0(0)$ & $8(1.6)$ \\
Total & $86(17.0)$ & $419(81.7)$ & $222(43.7)$ & $283(56.3)$ & $48(9.4)$ & $457(90.6)$ \\
$P$ & & 0.06 & & 0.1 & 0.1 &
\end{tabular}

* Abbreviations: VPB = ventricular premature beats SVPB = supraventricular premature beats Conduction disturbances include first and second degree atrioventricular block, left bundle branch block, right bundle branch block 
In the present study, there was no relationship between APOE genotype and blood pressure. Because CHD is a well-known etiological factor for AF [19], we examined the relationship between APOE genotype and ECG changes. There were no statistically significant associations between ECG changes and APOE genotype. Previous population-based studies have suggested that the $\varepsilon 4$ allele frequency is smaller in the elderly [20], possibly due to increased mortality of the $\varepsilon 4$ allele carriers [21]. The frequency of the $\varepsilon 4$ allele in the very elderly in the present study was, however only slightly lower $(15.3 \%)$ than previously shown frequency in the young Finnish subjects (19.4\%) [22]. The signs of CHD were not analysed on the recordings, as resting ECG is not reliable for detection of CHD. Thus the association between APOE genotypes and the extent atherosclerotic process in the arteries cannot be measured on the basis of our material. There are several possible aetiologies for AF in this age group, some of which are not associated with APOE polymorphism. There were no statistically significant association between other ECG changes and APOE genotypes.

These observations show that APOE genotype still influences cholesterol levels but not other cardiovascular risk factors such as blood pressure among the very elderly.

\section{Competing interests}

None declared.

\section{Authors' contributions}

SR participated in the design of the study, planning and reviewing of statistics and writing and editing the manuscript. KM participated in the study design, planning statistics and editing the manuscript. AV participated in the design of the study, collecting the data and editing the manuscript. LN participated to the co-ordinate and design the study. KJ participated in editing the manuscript. RS participated to co-ordinate the study and design and edit the manuscript. EL participated in planning the study and editing the manuscript.

All authors read and approved the final manuscript.

\section{Acknowledgements}

This study was supported by the grants from the Ministry of Education in Finland, The Centenary Foundation of Helsingin Sanomat, Finnish Neurology Association and Finnish Alzheimer Association. The authors wish to thank Mrs Pirkko Ahponen, R.N. for excellent fieldwork.

\section{References}

I. Davignon J, Gregg RE, Sing SF: Apolipoprotein E polymorphism and atherosclerosis. Arteriosclerosis I988, 8:I-2I.

2. Mahley RW: Apolipoprotein E: cholesterol transport protein with expanding role in cell biology. Science 1988, 240:622-630.

3. Uterman G, Kindermann I, Kaffarnik $\mathrm{H}$ et al.: Apolipoprotein E phenotypes and hyperlipidemia. Hum Genet 1984, 65:232-6.

4. Uterman G: Apolipoprotein E polymorphism in health and diseased. Am Heart J 1987, I 1 3:433-440.
5. Assman G, Schmitz G, Menzel H-J et al.: Apolipoprotein E polymorphism and hyperlipidemia. Clin Chem 1984, 30:64I-3.

6. Uusitupa M, Sarkkinen E, Kervinen K et al.: Apoliporotein E phenotype and blood pressure. The Lancet 1994, 343:57.

7. Couderc R, Mahieux F, Bailleul S et al.: Prevalence of Apolipoprotein $E$ phenotypes in Ischemic Cerebrovascular Disease. Stroke 1993, 24:66|-664.

8. Lilja MK, Kervinen K, Jounela AJ et al:: Apolipoprotein E Polymorphism in hypertensive patients: gene frequencies, plasma lipids and relation to antihypertensive drugs. Circulation 1989, 80:II-285.

9. Eto M, Watabane K, Makino I: Increased frequencies of apolipoprotein $\varepsilon 2$ and $\varepsilon 4$ alleles in patients with ischemic heart disease. Clinical genetics 1989, 36:183-188.

10. de Knijff P, Boomsma D, Feskens E et al.: Apolipoprotein E phenotype and blood pressure. The Lancet 1994, 342: 1234.

II. Syvänen A-C, Sajantila A, Lukka M: Identification of individuals by analysis of biallelic DNA markers using PCR and solid-phase minisequencing. Am J Hum Genet 1993, 52:46-59.

12. Kuusisto J, Koivisto K, Kervinen K, Mykkänen L, Helkala E-L, Vanhanen M, Hänninen T et al.: Association of apolipoprotein E phenotypes with late onset Alzheimer's disease: population based study. BM] 1994, 309:636-8.

13. Lehtinen S, Lehtimäki T, Sisto T, Salenius JP, Nikkilä M, Jokela H, koivula $T$, Ebeling F, Enholm C: Apolipoprotein E polymorphism, serum lipids, myocardial infarction and severity of angiographically verified coronary artery disease in men and women. Atherosclerosis 1995, I | 4:83-91.

14. Ilveskoski E, Perola M, Lehtimäki T, Laippala P, Savolainen V, Pajarinen J, Penttilä A, Lalu K, Koivula T, Karhunen PH, Mannikko A, Liesto KK: Age-dependent association of apolipoprotein $\mathrm{E}$ genotype with coronary and aortic atherosclerosis in middle-aged men: an autopsy study. Circulation 1999, 100:608-613.

15. Rantala M, Savolainen MJ, Kervinen K, Kesaniemi YA: Apolipoprotein $E$ phenotype and diet-induced alteration in blood pressure. Am J Clin Nutr 1997, 65:543-50.

16. Uusitupa M, Karhunen L, Rissanen A et al:: Apolipoprotein E phenotype modifies metabolic and hemodynamic abnormalities related to central obesity in women. Am J Clin Nutr 1996, 64: $13 \mid-6$.

17. Mahley RW: Apolipoprotein E: cholesterol transport protein with expanding role in cell biology. Science 1988, 240:622-40.

18. Sowers JR: Hypertension in the elderly. Am J Med 1987, 82(IB): I-8.

19. Camm AJ, Obel OA: Epidemiology and mechanism of atrial fibrillation and atrial flutter. Am J Cardiol 1996, 78(8A):3-II.

20. Louhija J, Miettinen HE, Kontula $\mathrm{K}$ et al.: Aging and genetic variation of plasma apolipoproteins. Relative loss of the apolipoprotein $\& 4$ phenotype in centenarias. Arterioscler Thromb 1994, I 4(7): 1084-9.

21. Corder E, Lannfelt L, Viitanen M, Corder L, Manton K, Winblad B, Basun H: Apolipoprotein E Genotype determines Survival in the Oldest Old (85 Years or Older) Who Have Good Cognition. Arch Neurol 1996, 53:4।8-422.

22. Lehtimäki T, Moilanen T, Viikari J, Åkerblom HK, Enholm C, Rönnemaa T, Marniemi J, Dahlen G, Nikkari T: Apolipoprotein E phenotypes in Finnish youths: a cross-sectional and six-year followup study. J Lipid res 1990, 3 1:487-495.

\section{Pre-publication history}

The pre-publication history for this paper can be accessed here:

http://www.biomedcentral.com/1471-2318/4/1/prepub 